\title{
Health Hazards
}

\section{Associated with the Use of Di-(2-Ethylhexyl) Phthalate (commonly referred to as DOP) in HEPA Filter Testing}

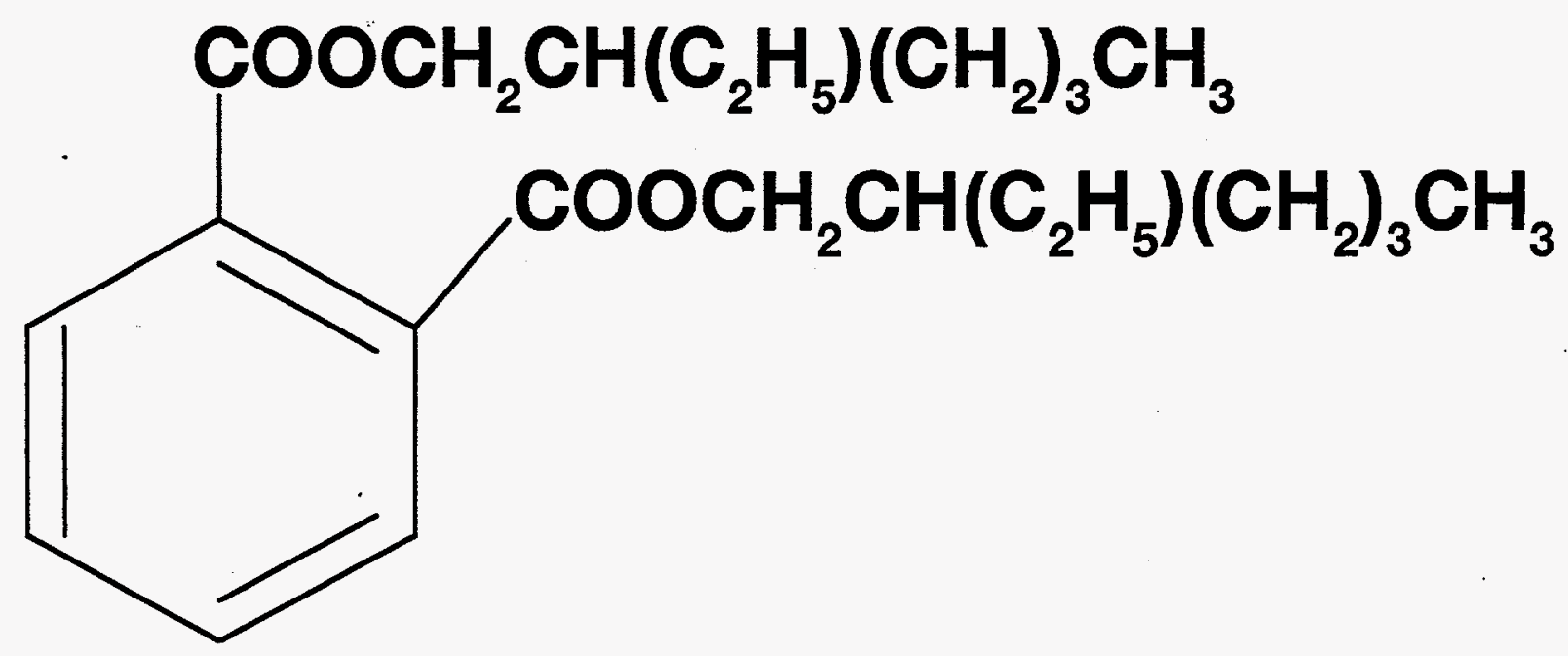

January 1995

U.S. Department of Energy

Office of Environment, Safety and Health

Washington, DC 20585 


\section{DISCLAIMER}

Portions of this document may be illegible electronic image products. Images are produced from the best available original document. 


\section{Contents}

Summary.$\ldots \ldots \ldots \ldots \ldots \ldots \ldots \ldots \ldots \ldots \ldots \ldots \ldots \ldots \ldots \ldots \ldots \ldots \ldots \ldots \ldots \ldots$

Chemical and Physical Properties of DEHP..........................

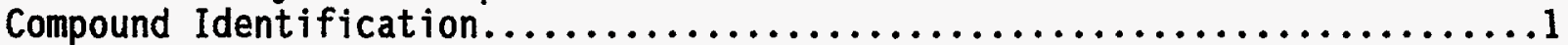

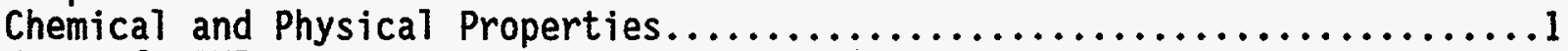

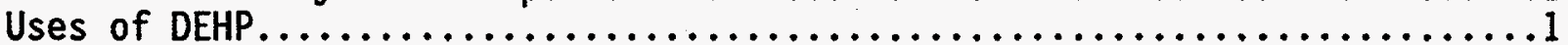

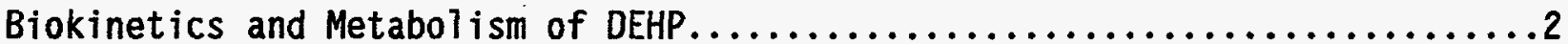

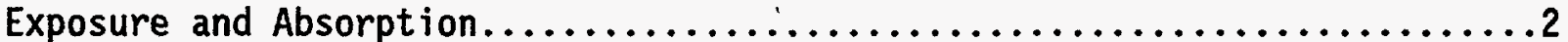

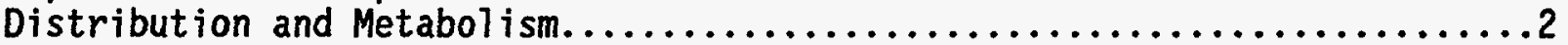

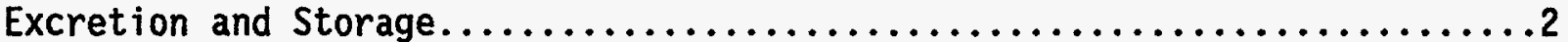

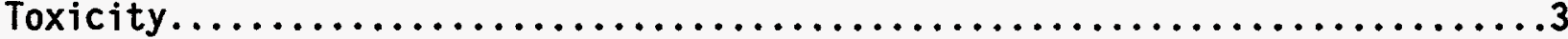

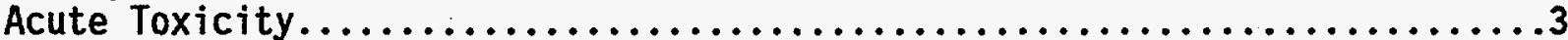

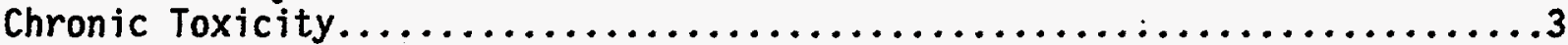

Mutagenicity and Carcinogenicity of DEHP......................

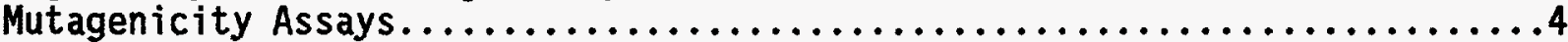

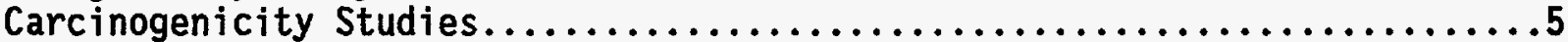

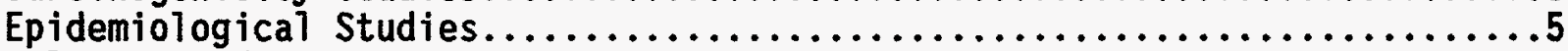

Regulatory and Advisory Agency Classifications of DEHP................ American Conference of Governmental Industrial Hygienists ACGIH) .......5

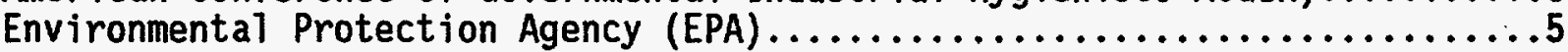

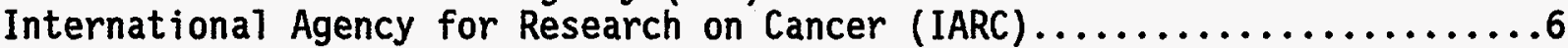

National Institute for Occupational Safety and Health (NIOSH) ..........6

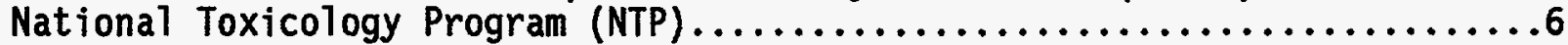

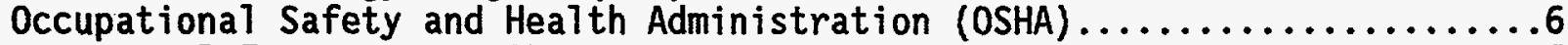

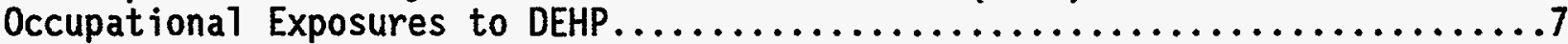

Historical Exposure Potential During Quantitative Respirator Fit Testing...7

Exposure Potential During HEPA Filter Testing....................8

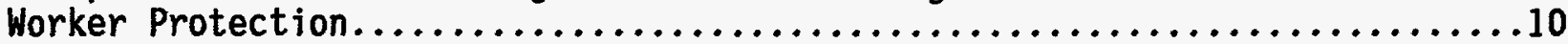

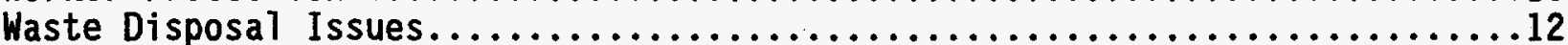

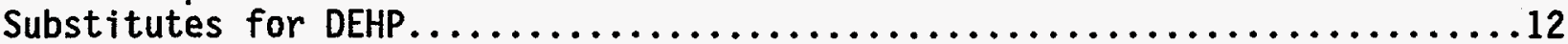

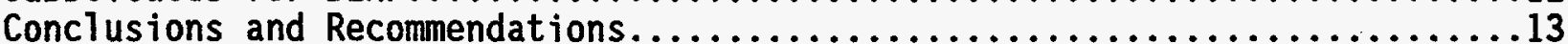

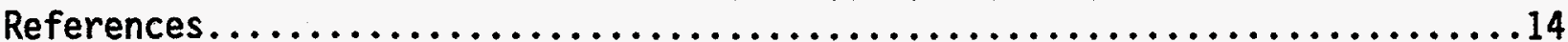

Figures and Tables:

Figure 1. Chemical Structure of DEHP............................ 19

Figure 2. Schematic Diagram of Typical In-Place HEPA Filter Test..........20

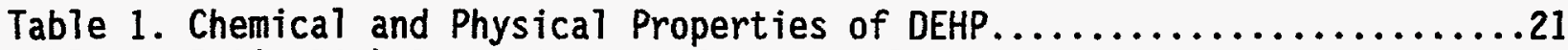

Table 2. EPA's Risk Per-Unit-Dose for Several Chemical Carcinogens.........22

Table 3. Occupational Exposure Standards and Guidelines for DEHP.........23

Table 4. Potential Routes of Exposure to DEHP During HEPA Filter Testing....24

Table 5. Properties of Several Potential DEHP Substitutes..............25

\section{DISCLAIMER}

This report was prepared as an account of work sponsored by an agency of the United States Government. Neither the United States Government nor any agency thereof, nor any of their employees, makes any warranty, express or implied, or assumes any legal liability or responsibility for the accuracy, completeness, or usefulness of any information, apparatus, product, or process disclosed, or represents that its use would not infringe privately owned rights. Reference herein to any specific commercial product, process, or service by trade name, trademark, manufacturer, or otherwise does not necessarily constitute or imply its endorsement, recommendation, or favoring by the United States Government or any agency thereof. The views and opinions of authors expressed herein do not necessarily state or reflect those of the United States Government or any agency thereof. 


\section{Surmary}

Di-(2-ethylhexy1) phthalate (DEHP), commonly referred to as di-octyl phthalate, is an important production chemical in the U.S. In addition to its major use as an additive in plastics, DEHP is widely used to evaluate the effectiveness of high efficiency particulate air (HEPA) filters. Historically, DEHP was also used in quantitative fit testing for respirators. Evaluations of this compound a decade ago showed that it can induce hepatocellular carcinomas in laboratory animals. Although most Department of Energy (DOE) facilities have since discontinued using DEHP in respirator fit testing, DEHP continues to be used for evaluating HEPA filters.

This report summarizes available information on the toxicity, mutagenicity, carcinogenicity, and other hazards and problems posed by DEHP, specifically with reference to HEPA filter testing. Information on work practice improvements as well as the availability and suitability of DEHP substitutes are also presented. This material should assist the DOE in the safe use of this material.

\section{Chemical and Physical Properties of DEHP}

Compound Identification

Di-(2-ethylhexy1) phthalate (DEHP) (CAS No. 117-81-7) (Figure 1) is a longchained member of the group of organic chemicals known as alkyl phthalates. DEHP is frequently referred to as di-octyl phthalate (DOP), which can be misleading because of possible confusion with an entirely different alkyl phthalate, di-n-octyl phthalate.

\section{Chemical and Physical Properties}

DEHP is a nearly colorless, odorless, viscous, oily liquid. It is highly stable and has a very low vapor pressure. Combined with a high liquid surface tension, this means that DEHP does not readily evaporate under ordinary room conditions. DEHP also has high boiling and flash points, and poses a negligible fire hazard. It is soluble in mineral oils, hexane, and various other organic solvents but is insoluble in water. Other chemical and physical properties of DEHP are summarized in Table 1.

Uses of DEHP

DEHP is an important production chemical. In the U.S., more than $10^{11}$ gatlons of it are produced annually, where the majority is used in the production of plastics and polymer films. Under prior sanctioning of the Delaney Clause, DEHP has been and continues to be approved by the U.S. Food and Drug Administration for use in medical and food packaging. DEHP is also used in insect repellents and pesticides, cosmetic formulations, detergents and soaps, inks, paints, and defoaming agents (NRCC 1980, IARC 1982). It also has 1 imited use as a vacuum pump oil, dielectric fluid, and a source of aerosols for testing air filters and their associated systems. Historically, DEHP was also used as a challenge aerosol for evaluating the facial fit of respirators. 


\section{Biokinetics and Metabolism of DEHP}

Exposure and Absorption

Phthalate esters are generally we11-absorbed from the gastrointestinal tract following ingestion. In rats, more than $50 \%$ of the DEHP administered orally is absorbed within 24 hours (Kluwe 1982). In their in vivo and in vitro work with rat, guinea pig, and human skin, Scott et al. (1987) and $\mathrm{Ng}$ et a1. (1992) experimental1y determined the dermal absorption rate for DEHP to range from about 0.3 to $2.2 \mathrm{ug} / \mathrm{cm}^{2} /$ hour, a low rate when compared with many other organic chemicals. Only a very smal1 fraction (about $7 \%$ ) of a skin bound dose is actually transported across the skin, leading $\mathrm{Ng}$ et al. (1992) to "... suggest that DEHP, because of high lipophilicity, has a tendency to remain in animal skin" and thus is poorly absorbed by this route. Although no data are available on the absorption of DEHP across lung tissue, the lipophilicity of this compound can be expected to facilitate such a mode of transport (Kluwe 1982). Given DEHP's low vapor pressure, the inhalation of vapors is unlikely to occur under normal conditions of temperature and pressure. However, the aerosols generated for HEPA filter testing have a sufficiently small particle size to ensure deep lung deposition, retention, and, potentially, absorption as well.

Distribution and Metabolism

Once absorbed into the blood stream, DEHP binds rapidly to blood proteins, principally lipoproteins, and is subsequently distributed throughout the body (Kluwe 1982). Fat, absorptive organs of the gastrointestinal tract, and the excretory organs (i.e., liver, kidney) serve as major initial repositories of this chemical. Like other phthalate esters, DEHP is rapidly hydrolyzed in the liver and gastrointestinal tract to its monoester metabolite, (mono-(2ethylhexy1) phthalate, or MEHP), accompanied by the release of an alcoholic derivative, 2-ethylhexano1 (ATbro and Thomas 1973, Kluwe 1982, Northrup et a1. 1982, Lhuguenot et a7. 1985, Pollack et a1. 1985). MEHP is further metabolized to a series of oxidation products (Lhuguenot et a1. 1985). However, despite these generalizations, marked variability in the rate, timedependency, and possible mechanisms for these biochemical reactions have been observed between different mammalian species (Albro et al. 1982, Lhuguenot et a1. 1985), making certain cross-species predictions difficult.

\section{Excretion and Storage}

Mammals eliminate DEHP primarily by urinary excretion, with a small fraction removed in the feces as well as by possible transfer to maternal milk. In general, DEHP tends to be rapidly cleared from the body, with the majority typically eliminated within 24 to 72 hours after absorption (Kluwe 1982). Al though there is little evidence for significant tissue accumulation of DEHP in rodents, chronic low-dose feeding studies in rhesus monkeys have showed longer-term retention of this chemical, notably in the liver (Jacobson et al. 1977). 


\section{Toxicity}

DEHP has been extensively evaluated for both acute and chronic toxicity. The following sections provide a brief summary of major findings for this compound. For more comprehensive reviews, see Clement Associates (1977), Daniel (1978), IARC (1982), Lawrence and Tuel1 (1979), Thomas et a7. (1978) as well as the specific works referenced below.

Acute Toxicity

DEHP shows very low acute toxicity in mammals. Single dose oral administration studies in mice, rats, guinea pigs, and rabbits have produced $\mathrm{LD}_{50}$ values ranging from about $25-40 \mathrm{~g} / \mathrm{kg}_{\mathrm{bw}}$ (Shaffer et a 1 . 1945, Krauskopf 1973, Lawrence et a7. 1975), indicating that DEHP is nearly non-toxic. Skin applications of DEHP to guinea pigs and rabbits show $L_{50}$ values in excess of $10 \mathrm{~g} / \mathrm{kg}_{\mathrm{bw}}$, and the compound is only slightly irritating to the eyes of rabbits (Shaffer et a1. 1945). These authors also reported that human volunteers who ingested from 5 to $10 \mathrm{~g}$ of DEHP experienced only mild gastric disturbances and loose stools.

\section{Chronic Toxicity}

Long-term feeding studies of DEHP in laboratory animals (1-2 year duration) have demonstrated a "lowest observable adverse effects leve1" ranging from about $20-100 \mathrm{mg} / \mathrm{kg}_{\text {boy }}$ (darpenter et a1. 1953, Harris et a1. 1956, Clement Associates 1977). Exposures above these levels produced reductions in body weight, increases in liver and kidney size and weight, and a variety of other effects as discussed below.

In 1982, the National Toxicology Program (NTP 1982) released the results of a two-year DEHP bioassay in rodents. DEHP was administered orally at levels of 3,000-6,000 ppm in mice and 6,000-12,000 ppm in rats. The results showed a decrease in mean body weight and the degeneration of seminiferous tubules in high-dosed male animals. Other studies have confirmed that high doses of DEHP as well as other related phthalate esters affect the male reproductive organs by depressing gonadal zinc levels, an important trace metal in the testes (Thomas et a1. 1982, Teirlynck et a1. 1988). Furthermore, the degree of testicular damage appears to be directly proportional to both the size of the dose and the length or duration of exposure (IARC 1982). Low levels of DEHP (i.e., several $\mathrm{mg} / \mathrm{kg}_{\mathrm{bw}} / \mathrm{day}$ ) can cause ant $\mathrm{i}$-fertility effects (Autian 1982) while high doses ( $\mathrm{i} . \mathrm{e}$., on the order of hundreds of $\mathrm{mg} / \mathrm{kg}_{\mathrm{bw}} / \mathrm{day}$ ) have been shown to be a reproductive toxicant and teratogen in female rodents (Singh et a1. 1972, Shiota and Nishimura 1982). At dietary levels of 3,000 ppm, DEHP can also significantly decrease fertility, reduce the proportion of 1 ive births, and induce mild teratogenic effects in laboratory animals. In their 1982 review of the toxicological literature on DEHP, the International Agency for Research on Cancer (IARC) concluded that "Di(2-ethylhexyl) phthalate can cause testicular damage in rats. There is evidence that this compound and its metabolite, mono(2-ethylhexyl) phthalate, are teratogenic and embryo-lethal to rodents." 
Gray and Beamand (1984) found that DEHP was incapable of inducing atrophy in testicular cell cultures, and instead suggested that a metabolite was responsible for this phenomenon. Albro et al. (1989) reported that, while both DEHP and its metabolite, MEHP, can cause acute testicular atrophy, "The present observations, when added to data already in the literature, support the conclusion that testicular atrophy resulting from exposure of rats to DEHP or MEHP is most probably due to MEHP itself." Heindel and Powel1 (1992) further evaluated the role of MEHP in testicular effects and determined that it inhibits enzyme activity in Sertoli cells. Numerous studies have showed that DEHP can affect a variety of other enzyme systems as well. Ohyama (1977) found that DEHP inhibits yeast glucose-6-phosphate dehydrogenase and related metabolic enzyme systems in vitro. In chronic feeding studies with male rats; low doses of DEHP (via metabolic derivatives of MEHP) increased the abundance of hepatic enzymes, including peroxisome proliferators (Ganning et a1. 1984, 1987, Mitchel1 et a1. 1985, Lake et a1. 1987). Peroxisome proliferators are a class of compounds that induce hepatic peroxisomes, single membrane-bounded cytoplasmic organelles that have been functionally-implicated in gluconeogenesis, lipid metabolism, and the detoxification of hydrogen peroxide and other oxygen radicals (Warren et al. 1982). The detection of an increase in the rate of production of these compounds can be interpreted as a cellmediated response to reactive oxygen species, chemicals known to be damaging to DNA. Peroxisome proliferators have been found to induce hepatomegaly and hypotriglyceridemia when fed to rodents. Yokota (1993) confirmed the observation that chronic administration of DEHP to rodents markedly induces the production of hepatic peroxisomes; however, he also noted that this activity rapidly declines upon withdrawal from a diet containing DEHP.

\section{Mutagenicity and Carcinogenicity of DEHP}

\section{Mutagenicity (Bacterial and In Vitro Cell Culture Studies)}

The results from mutagenicity testing of DEHP in bacterial systems, including Bacillus subtilis, Escherichia coli, and Salmonella typhimurium, have generally been negative (Agarwal et al. 1985, Kozumbo et al. 1982, Phillips et al. 1982, Seed 1982, Smith-01iver and Butterworth 1987, Warren et a1. 1982, Zeiger et a1. 1982, 1985). These assays were performed both in the absence and presence of rat liver homogenate ( $\mathrm{S}-9$ mixture) to simulate the influence of metabolic enzyme activity. In contrast to these findings, Tomita et al. (1982) showed that DEHP was mutagenic in the $S$. typhimurium assay in the presence (but not the absence) of $S-9$ mixture. They further demonstrated that the mutagenicity of the DEHP metabolite, MEHP, could be effectively eliminated by adding S-9. Phillips et al. (1982) also found that MEHP (but not DEHP) caused chromosomal damage in cultured Chinese hamster ovary cells (CHO). However, this phenomena occurred only with relatively high concentrations of MEHP (i.e., several hundred ppm) that also proved directly toxic to the cells. These findings are consistent with chronic toxicity data suggesting that DEHP is not a direct-acting mutagen, and that the observed effects are instead due to metabolically-derived MEHP. 
Carcinogenicity (Whole Animal Studies)

The most widely-referenced carcinogen bioassay of DEHP was conducted by the Carcinogenesis Testing Program of the National Cancer Institute (later incorporated into the National Toxicology Program) (NTP 1982). Groups of 50 of each sex of $\mathrm{F} 344$ rats and equal numbers of $\mathrm{B} 6 \mathrm{C} 3 \mathrm{~F}_{1}$ mice were fed diets containing DEHP. As described earlier under Chronic Toxicity, mice were fed either 3,000 or $6,000 \mathrm{ppm}$ and rats 6,000 or $12,000 \mathrm{ppm}$ of DEHP for two years. Treated female rats and all treated mice showed a statistically-significant, dose-related increase in the incidence of hepatocel7ular carcinomas over controls. In addition, dosed male rats showed a statistically-significant increase in the incidence of neoplastic nodules. These findings led the NTP to conclude that "Under the conditions of this bioassay, di(2-ethylhexyl) phthalate was carcinogenic for $\mathrm{F} 344$ rats and $\mathrm{B}^{6} \mathrm{C} 3 \mathrm{~F}_{1}$ mice ..."

Two earlier chronic exposure studies on DEHP also evaluated laboratory animals for tumorigenicity. Carpenter et a1. (1953) fed rats diets containing 400$4,000 \mathrm{ppm}$ of DEHP for one to two years, and diets of $1,300-4,000 \mathrm{ppm}$ of DEHP to guinea pigs and dogs for one year. Similarly, Harris et al. (1956) evaluated rats exposed to dietary levels of up to 5,000 ppm of DEHP for two years. Despite an absence of malignant tumors in treated animals in either study, the IARC's Working Group rejected these negative findings because of inadequate experimental design and insufficient study sample size (IARC 1982).

Epidemiology (Human Studies)

Thiess et a1. (1978) conducted an epidemiological study of 221 chemical production workers involved in the manufacture of DEHP. Airborne exposure levels of this chemical were not quantified, so the number of years worked was used as a surrogate for exposure. Deaths attributable to pancreatic carcinoma and uremia were significantly elevated among workers potentially exposed to DEHP for more than 15 years when compared to similariy aged cohorts in the general population. However, the study was limited by a short follow-up period and an absence of airborne exposure levels. As a result of these deficiencies, IARC's Working Group also rejected the findings of this study (IARC 1982).

\section{Regulatory and Advisory Agency CTassifications of DEHP}

American Conference of Governmental Industrial Hygienists (ACGIH) The ACGIH has indicated that DEHP is a "substance identified by other sources as a suspected or confirmed human carcinogen" but makes no further determination of its classification as a carcinogen. DEHP is reportedly under substance-specific evaluation by the ACGIH's TLV committee.

Environmental Protection Agency (EPA)

The Environmental Protection Agency has classified DEHP as a B2 "probable human carcinogen" based on evidence presented in the NTP's bioassay (EPA 1992). The EPA has also calculated quantitative risk estimates for exposures 
to DEHP using a linearized multistage model that incorporated "extra risk" (uncertainty factors). Under this model, the added risk of cancer per unit dose (slope factor) for oral exposure to DEHP was estimated at 0.014 per $\mathrm{mg} /\left(\mathrm{kg}_{\mathrm{bw}} / \mathrm{day}\right)$. This amounts to a $1.4 \%$ increase in the probability of developing cancer over a lifetime from the daily ingestion of $1 \mathrm{mg}$ of DEHP for every $\mathrm{kg}$ of body weight. For an average male weighing about $70 \mathrm{~kg}$ weight (154 pounds), this translates into the life-long, daily consumption of $70 \mathrm{mg}$ of DEHP. Table 2 shows the EPA's estimated risk per unit dose factors for several well-known chemicals. As indicated by comparison, even with the incorporation of conservative uncertainty factors, DEHP is classifiable as a low-potency carcinogen.

International Agency for Research on Cancer (IARC)

The International Agency for Research on Cancer (IARC 1982) determined that "There is sufficient evidence for the carcinogenicity of di(2-ethylhexyl) phthalate in mice and rats", leading them to designate DEHP as a Class 2B ("possible") human carcinogen.

National Institute for Occupational Safety and Health (NIOSH)

NIOSH has recommended that DEHP be treated as a potential human carcinogen.

National Toxicology Program (NTP)

The National Toxicology Program has classified DEHP as "reasonably anticipated to be" carcinogenic to humans, based upon the results of their two-year bioassay in mice and rats (NTP 1982).

Occupational Safety and Health Administration (OSHA)

The Occupational Safety and Health Administration's (OSHA) Hazard Communication standard (29 CFR Part 1910.1200, "HAZCOM") identifies carcinogens by reference to classifications made elsewhere. Specifically, HAZCOM states that chemicals classified as carcinogens by the IARC, NTP, or elsewhere by OSHA must be regulated as carcinogens. Thus, DEHP meets the HAZCOM definition of a carcinogenic chemical.

OSHA's Exposure to Hazardous Chemicals in Laboratories standard (29 CFR Part 1910.1450, "Laboratory Standard") defines a more restricted subset of carcinogens known as "select" carcinogens. Select carcinogens are chemicals that meet the following criteria:

- Regulated by OSHA as a carcinogen

- Listed as "known to be carcinogenic" by NTP

- Listed as a Group 1 (known human) carcinogen by IARC

- Listed as a Group $2 A$ or $2 B$ carcinogen by IARC or as "reasonably anticipated" to be a carcinogen by NTP and it causes a statistically significant incidence of tumors in experimental animals under the following exposure regimens:

- Inhalation of less than $10 \mathrm{mg} / \mathrm{m}^{3}$ for $6-7$ hours/day, 5 days/week, for a significant portion of the animal's lifetime

- $\quad$ Repeated skin applications of less than $300 \mathrm{mg} / \mathrm{kg}_{\mathrm{bW}} /$ week

- Oral intake of less than $50 \mathrm{mg} / \mathrm{kg}_{\mathrm{bw}} /$ day. 
Chemicals identified as select carcinogens require more stringent laboratory management and work practices, including designation of special handling areas for their use. However, based upon the above criteria, DEHP is not classifiable as a select carcinogen.

\section{Occupational Exposure to DEHP}

The National Institute for Occupational Safety and Health (NIOSH 1980) estimated that about 625,000 U.S. workers have exposure or the potential for exposure to DEHP, principally among workers in the plastics and chemical production industries. Estimates for the numbers of workers potentially exposed to DEHP during other operations and applications, including filter testing procedures, are not currently. available nor have results from worker exposure monitoring been published.

Table 3 shows exposure 1 imits for DEHP issued by various governmental agencies and advisory organizations. These limits were established to provide protection against possible chronic toxicity hazards from DEHP, not carcinogenicity.

Historical Exposure Potential During Quantitative Respirator Fit Testing Tens of thousands of workers and former workers from the DOE community may have received exposure to DEHP during quantitative respirator fit testing. Prior to the early $1980^{\prime} s$, DEHP was the agent of choice for generating aerosols for quantitative respirator fit testing. Workers wearing a respirator equipped with HEPA filters typically stood or sat in an enclosed chamber, into which DEHP aerosols were released. Particle quantity measurements were then collected inside and outside of the respirator. Using the ratio between facepiece and chamber particle counts, the actual fit factor was calculated for each particular respirator and worker. Test chamber concentrations periodically ranged upwards into scores of $\mathrm{mg} / \mathrm{m}^{3} \mathrm{DEHP}$. While properly fitted respirators would provide the wearers with adequate protection from the challenge agent, i11-fitting respirators could cause short-term inhalation exposures. In addition, poorly ventilated fit testing booths and their support areas could have contributed to chronic exposures to the technicians operating respiratory fit test programs.

On December 5, 1980, the DOE issued a memorandum entitled "National Toxicology Program Report on the Carcinogenesis Bioassay of DOP and Interim Guidance on Use of DOP as a Test Aerosol." In that memorandum, the Operational and Environmental Safety Division recommended that "The use of DOP to meet the quantitative fit testing requirements of respiratory protection programs should be suspended until a health hazard assessment can be made." The memorandum emphasized that substitute materials should be used wherever feasible. It further recommended that where DOP use remained necessary, engineering, work practice, and personal protective equipment controls should be used. The subsequent health hazard assessment concurred that DEHP is weakly carcinogenic in laboratory animals and encouraged that worker exposures 
to this compound be kept as low as reasonably achievable until acceptable substitute materials became available. Wide debate over the use of DEHP as a challenge agent for respirator fit testing led most DOE and non-DOE industrial hygiene groups to discontinue this practice and substitute corn oil or dioctyl sebacate for DEHP. Many facilities later adopted ambient particle counting systems that do not involve the generation of any challenge agents; instead, this system amplifies existing particles within a room through a condensation nuclei process.

Exposure Potential During HEPA Filter Testing HEPA filters, also known as "absolute" filters, are designed to remove particles from a contaminated airstream. Due to their general reliability and high level of performance, HEPA filters are commonly used in the nuclear field to prevent the release of radioactive particulates. HEPA filters are also used in laboratory fume hood and glove box systems, biological safety cabinets (to remove potentially-infectious bioaerosols), and on vacuum cleaners used to collect hazardous materials (e.g., asbestos debris).

Most institutions, including DOE and DOE-contractor facilities, evaluate the integrity and performance of HEPA filters according to recommendations established by the American Society of Mechanical Engineers (ASME) (Testing of Nuclear Air Treatment Systems, ASME N510-1989). This evaluation process involves challenging the filter with an aerosol and measuring the efficiency of particle removal. The traditional medium of choice for generating challenge aerosols has been DEHP. Aerosols of DEHP can be generated in either a compressed air or thermal block (heated) system. Both systems rely upon a series of specially-constructed nozzles to produce fine droplets of a reproducible particle size distribution.

Challenge aerosols are released at a point far enough upstream of the filter bank to provide uniform mixing in the airstream. After calibrating and zeroing the instrument, measurements are made of the challenge aerosol (upstream of the filter) and the cleaned air stream (downstream of the filter). These measurements are taken by sampling the air stream and counting the particle concentration, usually with a visible light photometer. Particle penetration and removal efficiency are then calculated.

HEPA filters are generally tested at two distinct stages of their operational history. In the DOE community, the first test occurs at one of two centralized Filter Test Facilities prior to the distribution of filters to end-users. This quality assurance test evaluates HEPA filters under controlled conditions to ensure that the filters meet their as-manufactured specifications. In order to receive approval and be released to field users, HEPA filters must demonstrate a particle removal efficiency of $\geq 99.97 \%$ when challenged with an aerosol containing essentially mono-dispersed particles with a diameter of 0.3 um.

HEPA filters are again evaluated after installation at their end-user facility (Figure 2). This testing, known as "in-place" testing, evaluates not only the 
filter but also the filter housing, associated seals and gaskets, and the integrity of the supporting ductwork. The procedure for in-place leakage testing is somewhat different from quality assurance testing. Specifically, the aerosol used for in-place testing must show a polydisperse particle size distribution with the following characteristics:

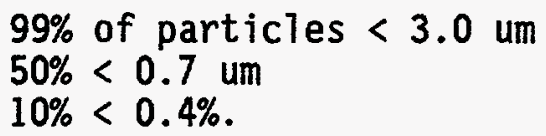

The typical acceptance criteria for in-place testing is a removal efficiency of $99.95 \%$ or higher. This value is the product of the quality assurance criteria of $\geq 99.97 \%$ and a system criteria of equal stringency, i.e., $99.97 \%$ of $99.97 \%$, which equals $99.95 \%$.

In-place HEPA filter testing is typically performed annually, although critical filtration systems may be tested more frequently. During the inplace test, additional information is collected about the system, including a visual inspection of the filter housing, gasketing material, ductwork, and the static pressure loss across the filter as an indication of particle loading. In-place testing must also be repeated whenever a HEPA filter system is modified or altered to ensure that the particle removal efficiency has not been affected.

Given that most facilities with HEPA filter systems have at least one technician assigned to the testing of these systems, a rough estimate of workers potentially exposed by this operation can be made. In the U.S., there are approximately 100 operational nuclear power stations, several dozen DOE installations, and on the order of several thousand other research institutions, biotechnology firms, medical and electronic clean rooms, and other facilities that operate at least one HEPA filtration system. Together, such a rough estimate would indicate that at least 5,000 to 10,000 workers directly test and evaluate HEPA filter systems. This estimate could increase by a factor of as much as 10 if other maintenance and support workers with access to these systems are included.

HEPA filter testing is a relatively simple and direct procedure, but it presents numerous opportunities for worker exposures to occur. Table 4 gives an overview of the places and activities that could potentially cause occupational exposure during HEPA filter testing. By enforcing ordinary practices of personal hygiene and providing workers with a minimal 1evel of personal protective equipment, it should be possible to nearly eliminate exposure to DEHP by ingestion and dermal contact. The remaining route of exposure, inhalation, requires a greater level of attention since it is probably the more prevalent and hazardous route.

The location of most HEPA filter systems on the negative pressure side of a fan blower should greatly reduce the potential for inhalation exposures to workers. However, exposure can still occur if the generator leaks due to 
improper assembly or damage. In addition, aerosols may be inadvertently released into the work area by starting the generator prior to insertion of the delivery hose into ductwork, or by removing the delivery hose before the generator has been shut off. In either case, a high concentration of DEHP aerosols can be released directly into the work area. Aerosols may also become reentrained in the work area if the system is located on the positive pressure side (e.g., downstream) of the fan. Under these conditions, perforations and unsealed areas of the ductwork will act as conduits for aerosols to leak into the work area.

\section{Worker Protection}

The basic principles of good industrial hygiene practice establish a hierarchy of preferred methods for protecting workers from a hazard. In order of typical control efficiency and preference, these are:

- Product or process elimination

- Product or process substitution

- Institution of engineering controls

o Use of personal protective equipment.

Eliminating HEPA filter testing would be the most efficient method for protecting the health and safety of workers. However, since testing remains necessary to ensure the adequate performance of HEPA filter systems, and challenge aerosols are the only currently-accepted method for conducting these tests, the process cannot be eliminated. Substitution of DEHP with a less dangerous material or practice would also be an effective method for eliminating occupational exposure to this compound. As described below in the section Substitutes for DEHP, several compounds have been identified as suitable substitutes for DEHP in HEPA filter testing procedures. These compounds have not demonstrated potential carcinogenicity and are considered relatively non-toxic. Nevertheless, exposure to DEHP may continue into the future. A combination of engineering, personal protective equipment, and work practice controls should be adequate to protect workers.

New HEPA filtration systems should be designed with challenge aerosol testing procedures in mind. Specifically, systems should be built so that challenge aerosols can be released upstream of the fan to maintain negative pressure at the release port. This will minimize the potential for fugitive emissions and worker exposure. Aerosol release and sampling ports should be labelled and the direction of air flow indicated. HEPA filters tested with DEHP should also be labelled to ensure that maintenance and hazardous waste management workers are fully apprised of the potential hazard present.

A comprehensive standard operating procedure (SOP) should be prepared for HEPA filter testing. This SOP should include requirements for worker training on the hazards of DEHP, proper work practices, personal protective equipment, and emergency response actions. 
At the minimum, gloves and splash-proof safety goggles should be worn while filling the aerosol generator. Gloves manufactured from nitrile, buty?, natural rubber, neoprene, and viton all offer good resistance to DEHP permeation (Schwope et a1. 1987). A disposable laboratory coat or jumpsuit made of chemically-resistant material (e.g., Tyvek) should provide adequate outerwear protection. The very low vapor pressure of this compound will generally make the use of respiratory protection unnecessary. Any leaks or spillage should be wiped off and the area cleaned with a suitable agent (e.g., detergent mixture, alcohol). All fittings and hoses should be replaced and sealed (e.g., pipe thread tape). The generator should be transported in a manner that minimizes the potential for damage and spills.

Aerosols should only be generated after the delivery nozzle has been inserted into the release port. If the port is under negative pressure (i.e., upstream of the fan), reentrainment back into the work area is unlikely to occur unless the release rate significantly exceeds the airflow rate. However, if the port is under positive pressure, the delivery nozzle should be sealed in place with duct tape. Aerosol generation should begin at a slow rate and air pressure gradually increased until the proper delivery rate is achieved. Where experience or monitoring has indicated the potential for an inhalation hazard (i.e., delivery on positive pressure side of fan, damaged or leaky ductwork, etc.), respiratory protection may also be required. A7though HEPA filtered half-face respirators should provide an adequate level of protection, workers should be periodically monitored for exposure to DEHP (i.e., NIOSH Method 5020). This will help to establish a baseline reference as well as provide quantitative information on the appropriateness of selected personal protective equipment.

When the test is completed, the generator should be shut down and allowed to purge for several minutes before removing the delivery nozzle from the release port. Gloves should be worn while removing the delivery nozzle from the port and care taken to avoid dripping. The nozzle should be wrapped in a heavygrade polyethylene plastic bag and sealed to prevent the spread of liquid DEHP.

In the event of a documented over-exposure, evidence of visible aerosols of DEHP in the work area, or the development of signs or symptoms associated with over-exposure to DEHP, workers should be instructed to immediately contact the occupational health clinic, their supervisor, and other appropriate professionals (e.g., industrial hygienists) for assistance and medical followup.

In the event of a spi11, responders must wear appropriate personal protective clothing (i.e., splash-proof safety goggles and permeation-resistant gloves, outerwear, and shoe covers. Again, the low vapor pressure of liquid DEHP makes inhalation exposure unlikely. Clean-up should proceed from the perimeter of the spill inward. Spilled material and clean-up supplies should be collected for disposal as hazardous waste. The spill site should then be washed and wiped down with a suitable cleaning agent. 


\section{Waste Disposal Issues}

A recent problem involving the use of DEHP in HEPA filter testing is the restriction against land disposal of "mixed" waste (i.e., waste containing both radioactive and hazardous chemical constituents). At the majority of DOE facilities, HEPA filters are used to remove radioactive particulate matter from contaminated fume hood and nuclear plant exhaust systems. Testing these systems with a chemical classified as a carcinogen (and regulated as a "Tisted" hazardous waste by the U.S. EPA, Hazardous Waste No. U028) therefore produces a recognizable mixed waste that is subject to disposal restrictions at DOE as well as commercial low-level radioactive waste disposal sites. While process knowledge information can be used to establish how much DEHP could potentially have been loaded onto a HEPA filter, many spent HEPA filters continue to be managed as mixed waste. Limited laboratory experimentation has shown that aerosolization of DEHP also produces vaporized DEHP (about $7 \%$ of the total stream) which readily penetrates HEPA filters (Smith et a1. 1980). However, specific information regarding the long-term retention of DEHP on HEPA filters, especially under the conditions of high volume air flow typically found in an exhaust system, is not currently available.

\section{Substitutes for DEHP}

Although a variety of procedures (e.g., engineering controls, personal protective equipment, work practice guidelines) can be used to minimize worker exposure to DEHP, product substitution ultimately offers the most expedient and efficient method for minimizing occupational hazards during HEPA filter testing operations. Over the past decade, numerous chemicals have been proposed as alternatives to DEHP, including corn and other vegetable oils, the related compound di-octyl sebacate (DOS), various polyethylene glycols, and several natural and synthetic hydraulic fluids (Smith et al. 1980, Hinds et a1. 1982a, 1982b, Scripsick and Soderholm 1987, Carlon et a1. 1991, Carlon and Gue 7 ta 1992a, 1992b, Steffen and Girres 1992). Table 5 provides an overview of several of these potential substitute compounds.

Earlier versions of the ASME standard, "Testing of Nuclear Air Treatment Systems", specifically required the use of DEHP aerosols and thus posed a barrier to the ready substitution of DEHP with other, less harmful, compounds. The current revision of this document identifies DEHP as the standard compound but it also provides particle size distribution criteria for identifying acceptable alternatives. In addition, it references a published article on the particle size distributions for several potential DEHP substitutes. Despite the demonstrated efficacy of several substitute chemicals, and the adoption of one of them by the U.S. Army (Emery 3004, a synthetic hydraulic fluid)(Carlon et a7. 1991, Carlon and Guelta 1992a, 1992b), many facility managers remain hesitant to modify their HEPA filter testing procedures for technical reasons as well as concerns over the potential outcome of DOEsponsored audits and inspections. 


\section{Conclusions and Recommendations}

Under the definitions of classical toxicology, DEHP shows very low acute toxicity. The compound generally fails to produce mutations in bacterial and mammalian cell culture systems; however, some evidence exists to suggest that one of the metabolic products of DEHP is mutagenic. Despite its low potency, DEHP has also been shown to induce hepatocellular carcinomas under chronic, high-dose oral administration in laboratory rodents. On the basis of this data, various internationally-recognized advisory organizations and governmental agencies have classified DEHP as a potential human carcinogen.

Given this information and an absence of specific inhalation and human risk data, the prudent course of action is to treat DEHP as a suspect human carcinogen. As with other suspect human carcinogens, industrial hygienists and other health and safety professionals should take additional precautions to protect workers who handle DEHP. This is especially true for workers involved in HEPA filter testing, where respirabie aerosols of this chemical are purposefully generated at high concentrations. Until other, less hazardous chemicals are substituted for DEHP, the following precautions should be instituted:

- Develop and distribute site-specific work practice guidelines for handling DEHP that include appropriate work practices and personal protective equipment requirements;

o Identify job classifications with the potential for exposure to DEHP;

- Characterize worker exposures to DEHP using personal monitoring (i.e., NIOSH Method 5020) to establish baseline reference and ensure that personal protective equipment requirements afford adequate protection. 


\section{References}

Albro, P.W. and R.0. Thomas. 1973. Enzymatic hydrolysis of di(2-ethylhexyl) phthalate by 1ipases. Biochimica Biophysica Acta 360:380-390.

Albro, P.W., S.T. Jordan, J.L. Schroeder, and J.T. Corbett. 1982. Chromatographic separation and quantitative determination of the metabolites of di(2-ethylhexy1) phthalate from urine of laboratory animals. Journal of Chromatography 244:65-79.

Albro, P.W., R.E. Chapin, J.T. Corbett, J. Schroeder, and J.L. Phelps, 1989. Mono-2-ethylhexyl phthalate, a metabolite of di-(2-ethylhexyl) phthalate, causally linked to testicular atrophy in rats. Toxicology and Applied Pharmacology 100:193-200.

Agarwa1, D.K., W.H. Lawrence, L.J. Nunez, and J. Autian. 1.985. Mutagenicity evaluation of phthalic acid esters and metabolites in Salmonella typhimurium cultures. Journal of Toxicology and Environmental Health 16:61-69.

American Conference of Governmental Industrial Hygienists (ACGIH). 1991. Documentation of the Threshold Limit Values and Biological Exposure Indices, Sixth Edition. ACGIH, Cincinnati, OH.

American Society of Mechanical Engineers (ASME). 1989. Testing of Nuclear Air Treatment Systems, ASME N510-1989. ASME, New York, NY.

Autian, J. 1982. Antifertility effects and dominant lethal assays for mutagenic effects of DEHP. Environmental Health Perspectives 45:115-118.

Carlon, H.R., M.A. Guelta, and B.V. Gerber. 1991. Some candidate replacement materials for dioctyl phthalate in "hot smoke" aerosol penetrometer machines. Aerosol Science and Technology 14:233-246.

Carion, H.R. and M.A. Guelta. 1992a. An update: DOP replacement in testing machines for filters and respirators. 22nd DOE/NRC Nuclear Air Cleaning and Treatment Conference.

Carlon, H.R. and M.A. Guelta. 1992b. Implementation of DOP Replacement with Selected Materials in Mask and Filter Testing Penetrometer Machines: Final Report. U.S. Army Chemical Research, Development, and Engineering Center, Report No. CRDEC-TR-370. Aberdeen Proving Grounds, MD.

Carpenter, C.P., C.S. Weil, and H.F. Smyth. 1953. Chronic oral toxicity of di(2-ethylhexyl) phthalate for rats, guinea pigs, and dogs. Archives of Industrial Hygiene and Occupational Medicine 8:219-226.

Clement Associates, Inc. 1977. Dossier on A7kyl Phthalates. Prepared for the TSCA Interagency Testing Committee, Washington, D.C.

Danie1, J.W. 1978. Toxicity and metabolism of phthalate esters. Clinical Toxicology 13:257-268. 
Environmental Protection Agency (EPA). 1992. Di(2-Ethylhexy7) Phthalate (DEHP). Integrated Risk Information System (IRIS) Database. EPA, Washington, DC.

Ganning, A.E., V. Brunk, and G. Dallner. 1984. Phthalate esters and their effect on the liver. Hepatology 4(3):541-547.

Ganning, A.E., U. Brunk, C. Edlund, A. Elhammer, and G. Dallner. 1987. Effects of prolonged administration of phthalate ester on the liver. Environmental Hea7th Perspectives 73:251-258.

Gray, T.J.B. and J.A. Beamand. 1984. Effect of some phthalate esters and other testicular toxins on primary cultures of testicular cells. Food and Cosmetics Toxicology 22:123-131.

Harris, R.S., H.C. Hodge, E.A. Maynard, and H.J. Blanchet, Jr. 1956. Chronic oral toxicity of 2-ethylhexyl phthalate in rats and dogs. Archives of Industrial Health 13:259-264.

Heindel, J.J., and C.J. Powe11. 1992. Phthalate ester effects on rat Sertoli cell function in vitro: Effects of phthalate side chain and age of animal. Toxicology and Applied Pharmacology 115:116-123.

Hinds, W.C., J.M. Macher, and M.W. First. 1982a. Size distributions of test aerosols produced from materials other than DOP. The Journal of Environmental Sciences May/June issue:20-21.

Hinds, W.C., J.M. Macher, and M.W. First. 1982b. Size distributions of aerosols produced by the Laskin aerosol generator using substitute materials for DOP. American Industrial Hygiene Association Journat 44(7):495-500.

International Agency for Research on Cancer (IARC). 1982. IARC Monographs on the Evaluation of the Carcinogenic Risk of Chemicals to Humans. Some Industrial Chemicals and Dyestuffs. Volume 29. IARC, Lyon, France.

Jacobson, M.S., S.V. Kevy, and R.J. Grand. 1977. Effects of a plasticizer leaked from polyvinyl chloride on the subhuman primate: a consequence of chronic transfusion therapy. Journal of Laboratory and Clinical Medicine 89:1066-1079.

Kluwe, W.M. 1982. Overview of phthalate ester pharmacokinetics in mammalian species. Environmental Health Perspectives 45:3-10.

Kluwe, W.M., E.E. McConnel1, J.E. Huff, J.K. Haseman, J.F. Douglas, and W.V. Hartwe11. 1982. Carcinogenicity testing of phthalate esters and related compounds by the National Toxicology Program and the National Cancer Institute. Environmenta7 Hea7th Perspectives 45:129-133.

Kozumba, W.J., R. Kroll, and R.J. Rubin. 1982. Assessment of the mutagenicity of phthalate esters. Environmental Health Perspectives 45:103-109. 
Krauskopf, L.G. 1973. Studies on the toxicity of phthatates via ingestion. Environmental Health Perspectives 3:61-72.

Lake, B.G., S.L. Kozlen, J.G. Evans, T.J.B Gray, P.J. Young, and S.D.

Gango17i. 1987. Effect of prolonged administration of clofibric acid and di(2-ethylhexyl) phthalate on hepatic enzyme activities and lipid peroxidation in the rat. Toxicology 44:213-228.

Lawrence, W.H., M. Malik, J.E. Turner, A.R. Singh, and J. Autian. 1975. A toxicological investigation of some acute, short-term and chronic effects of administering di-2-ethylhexyl phthalate (DEHP) and other phthalate esters. Environmental Research 9:1-11.

Lawrence, W.H. and S.F. Tue17. 1979. Phthalate esters: The question of safety - an update. Clinical Toxicology 15(4):447-466.

Lhuguenot, J.C., A.M. Mitche11, G. Milner, E.A. Ock, and C.R. Elcombe. 1985. The metabolism of di(2-ethylhexy1) phthalate (DEHP) and mono-(2-ethylhexy1) phthalate (MEHP) in rats: in vivo and in vitro dose and time dependency of metabolism. Toxicology and Applied Pharmacology 80:11-22.

Mitche11, A.M., J.C. Lhuguenot, J.W. Bridges, and C.R. Elcombe. 1985. Identification of the proximate peroxisome proliferator(s) derived from di(2ethylhexyl) phthalate. Toxicology and Applied Pharmacology 80:23-32.

National Institute for Occupational Safety and Health (NIOSH). 1980. Projected Number of Occupational Exposures to Chemical and Physical Hazards. Cincinnati, $\mathrm{OH}$.

National Research Council Canada (NRCC). 1980. Phtha7ate Esters in the Aquatic Environment. NRCC No. 17583, Ottawa, Canada.

National Toxicology Program (NTP). 1982. Carcinogenesis Bioassay of Di(2Ethylhexyl) Phthalate (CAS No. 117-81-7) in F344 Rats and B6C3F1 Mice (Feed Study). NTP Report No. PB82-184011. NTP, Research Triangle Park, NC.

Ng, K.M.E., I. Chu, R.L. Bronaugh, C.A. Franklin, and D.A. Somers. 1992. Percutaneous absorption and metabolism of pyrene, benzo[a]pyrene, and di(2ethylhexy1) phthalate: Comparison of in vitro and in vivo results in the hairless guinea pig. Toxicology and Applied Pharmacology 115:216-223.

Northrup, S., L. Martis, R. Ulbrecht, J. Garber, J. Miripol, and T. Schmitz. 1982. Comment on the carcinogenic potential of di(2-ethylhexy1) phthalate. Journal of Toxicology and Environmental Health 10:493-518.

Ohyama, T. 1977. Effects of phthalate esters on glucose-6-phosphate dehydrogenase and other enzymes in vitro. Toxicology and Applied Pharmacology 40:355-364. 
Phillips, B.J., T.E.B. James, and S.D. Gangolli. 1982. Genotoxicity studies of di(2-ethylhexy1) phthalate and its metabolites in CHO cells. Mutation Research 102:297-304.

Pollack, G.M., R.C. Li, J.C. Ermer, and D.D. Shen. 1985. Effects of route of administration and repetitive dosing on the disposition kinetics of di-(2ethylhexyl) phthalate and its mono-de-esterified metabolite in rats.

Toxicology and Applied Pharmacology 79:246-256.

Schwope, A.D., P.P. Costas, J.0. Jackson, J.0. Stull, and D.J. Weitzman. 1987. Guidelines for the Selection of Chemical Protective Clothing, Third Edition. American Conference of Governmental Industrial Hygienists, Cincinnati, $\mathrm{OH}$.

Scott, R.C., P.H. Dugard, J.D. Ramsey, and C. Rhodes. 1987. In vitro absorption of some o-phthalate diesters through human and rat skin. Environmental Health Perspectives 74:223-227.

Scripsick, R.C. and S.C. Soderholm. 1987. Final Report: Evaluation of Methods, Instrumentation, and Materials Pertinent to Quality Assurance Filter

Penetration Testing. Report No. LA-10748. Los Alamos National Laboratory, Los Alamos, NM.

Seed, J.L. 1982. Mutagenic activity of phthalate esters in bacterial 1 iquid suspension assays. Environmental Health Perspectives 45:111-114.

Shaffer, C.B., C.P. Carpenter, and H.F. Smyth, Jr. 1945. Acute and subacute toxicity of di(2-ethylhexy1)phthalate with note upon its metabolism. Journal of Industrial Hygiene and Toxicology 27:130-135.

Shiota, K. and H. Nishimura. 1982. Teratogenicity of di-2-ethylhexyl phthalate and di-n-butyl phthalate in mice. Environmental Health Perspectives 45:65-70.

Singh, A.R., W.H. Lawrence, and J. Autian. 1972. Teratogenicity of phthalate esters in rats. Journal of Pharmacological Sciences 61:51-55.

Smith, J.P., P.A. Baron, L.J. Doemeny, D.C. Sterling, E. Kennedy, L.D. Reed. 1980. DOP Substitutes for Quantitative Fit Testing: Aerosol Generation and Detection. PB83-137992. U.S. Department of Health and Human Services, PHS, CDC, NIOSH, Cincinnati, OH.

Smith-01iver, T. and B.E. Butterworth. 1987. Correlation of the carcinogenic potential of di(2-ethylhexyl) phthalate (DEHP) with induced hyperplasia rather than with genotoxic activity. Mutation Research 188:21-28.

Steffen, D.H. and C.K. Girres. 1992. Emery 3004 as a Challenge Aerosol: Operational Experience at Westinghouse Hanford Company. Report No. WHC-SA-1509 (DE93-004987). Westinghouse Hanford Company, Richland, WA. 
Teirlynck, O., J.M. Kaufman, M.G. Bogaert, and H. Roe1s. 1988. Testicular toxicity induced by single dosing of di- and mono(2-ethylhexy1) phthalate in the rat. Toxicology Letters 40:85-91.

Thiess, A.M., R. Frentzel-Beyme, and R. Wieland. 1978. Mortality study in workers exposed to di-(2-ethylhexy1) phthalate (DOP). In: Possibilities and Limits of Biological Monitoring: Problems of Occupational Medicine in Small Industries, Colloquium in Occupational Medicine. Frankfurt, Germany. (translated from German) Thomas, J.A., T.D. Darby, R.F. Wallin, P.J. Garvin, and L. Martis. 1978. A review of the biological effects of di-(2-ethylhexy1) phthalate. Toxicology and Applied Pharmacology 45:1-27.

Thomas, J.A., K.A. Curto, and M.J. Thomas. 1982. MEHP/DEHP: Gonadal toxicity and effects on rodent accessory sex organs. Environmental Health Perspectives 45:85-88.

Tomita, I., Y. Nakamura, and Y. Yagi. 1977. Phthalic acid esters in various foodstuffs and biological materials. Ecotoxicology and Environmental Safety $1: 275-287$.

Tomita, I, Y. Nakamura, N. Aoki, and N. Inui. 1982. Mutagenic/carcinogenic potential of DEHP and MEHP. Environmental Health Perspectives 45:119-125.

Warren, J.R., N.D. La7wani, and J.K. Reddy. 1982. Phthalate esters as peroxisome proliferator carcinogens. Environmental Health Perspectives 45:3540 .

Yokota, S. 1993. Formation of autophagosomes during degradation of excess peroxisomes induced by administration of dioctyl phthalate. European Journal Cell Biology 61:67-80.

Zeiger, E., S. Haworth, W. Speck, and K. Mortelmans. 1982. Phthalate ester testing in the National Toxicology Program's environmental mutagenesis test development program. Environmental Health Perspectives 45:99-101.

Zeiger, E., S. Haworth, K. Mortelmans, and W. Speck. 1985. Mutagenicity testing of di(2-ethylhexyl) phthalate and related chemicals in Salmonella. Environmental Mutagenesis 7:213-232. 
Figure 1. Chemical structure of di-(2-ethylhexyl) phthalate.

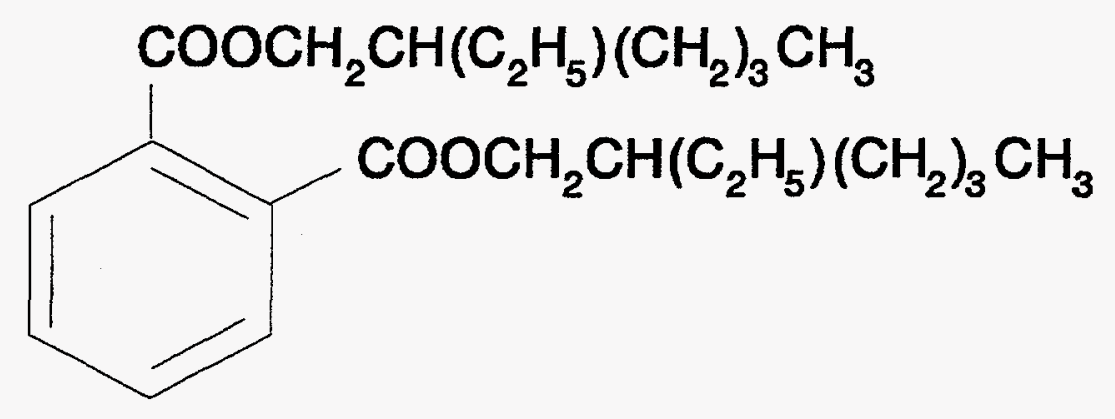


Figure 2. Diagram of a typical in-place HEPA filter test.

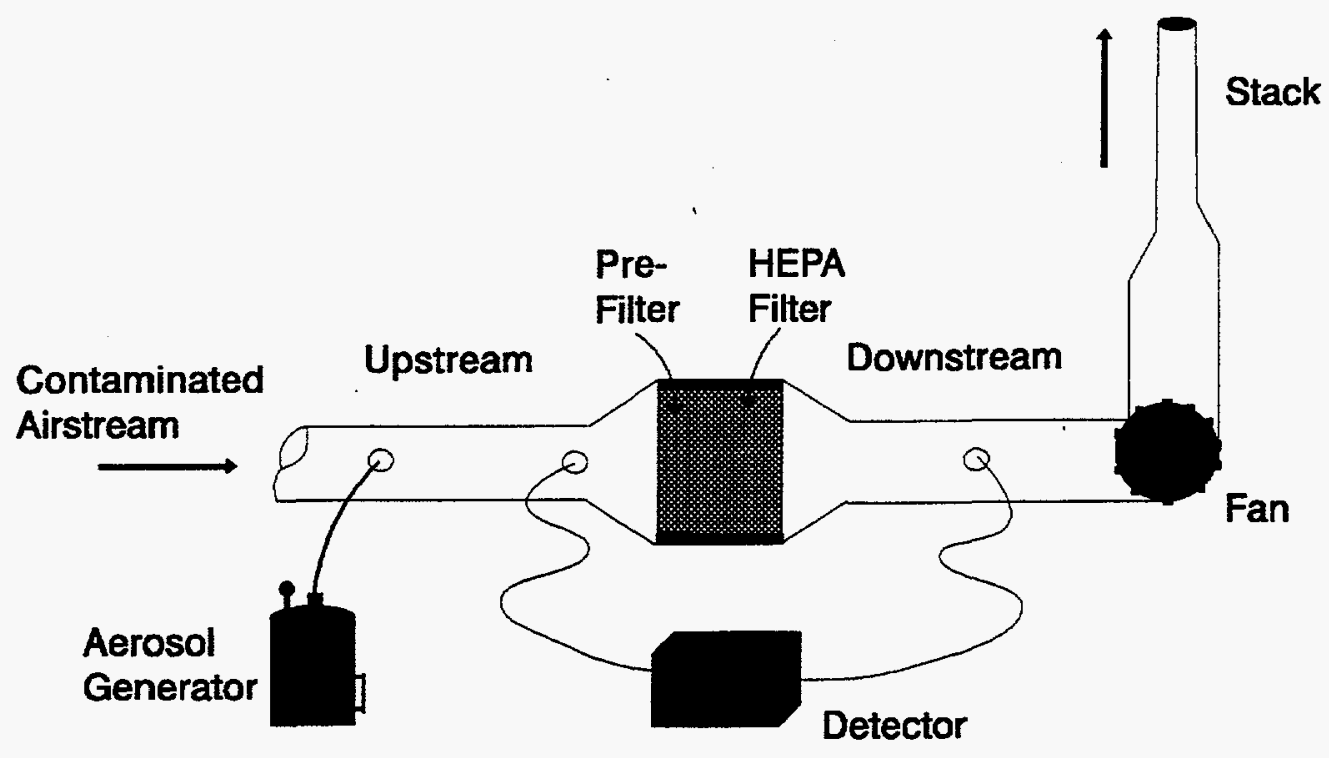


Table 1. Chemical and physical properties of di-(2-ethylhexy1) phthalate (DEHP).

Molecular weight

Empirical formula

Density $(\mathrm{g} / \mathrm{mL})$ e $20{ }^{\circ} \mathrm{C}$

Form o $20^{\circ} \mathrm{C}$

Stability

Boiling point

Flash point

Autoignition temperature

Vapor pressure e $20^{\circ} \mathrm{C}$

Liquid surface tension

Viscosity $20^{\circ} \mathrm{C}$

Solubility

Odor
390.5

$\mathrm{C}_{24} \mathrm{H}_{38} \mathrm{O}_{4}$

0.986

Liquid

Highty stable

$384{ }^{\circ} \mathrm{C}\left(724{ }^{\circ} \mathrm{F}\right)$

$215^{\circ} \mathrm{C}\left(420^{\circ} \mathrm{F}\right)$

$390^{\circ} \mathrm{C}\left(735^{\circ} \mathrm{F}\right)$

$<1 \mathrm{~mm} \mathrm{Hg}$

-30 dynes/cm

81.4 centipoises

Mineral oils, hexane

(insoluble in water)

slight "oily" odor 
Table 2. The EPA's calculated risk per-unit-dose (slope factor) for several chemical carcinogens (EPA 1992). The risk per-unit-dose shows the incremental, additive increase in cancer likely to develop from ingestion of 1 $\mathrm{mg} / \mathrm{kg}_{\mathrm{bw}} /$ day of a chemical over a person's lifetime. The higher the slope factor, the more "potent" or capable of inducing cancer the compound is.

\begin{tabular}{lc}
\hline Chemical or Compound & Slope \\
& Factor \\
\hline Methylene chloride & 0.0075 \\
DEHP & 0.014 \\
Benzene & 0.029 \\
DDT & 0.34 \\
Chlordane & 1.3 \\
Benzo[a]pyrene & 5.79 \\
Benzidine & 230 \\
Diethylstilbestrol (DES) & 4,700 \\
TCDD (dioxin) & 150,000 \\
& \\
\hline
\end{tabular}


Table 3. Occupational exposure standards and guidelines for di(2-ethylhexyl) phthalate (DEHP).

\begin{tabular}{lll}
\hline & \multicolumn{2}{c}{ Exposure Limit $\left(\mathrm{mg} / \mathrm{m}^{3}\right)$} \\
\cline { 2 - 3 } Agency or Group & $\begin{array}{l}8-\text { hour } \\
\text { TWA }\end{array}$ & $\begin{array}{c}15-\mathrm{minutes} \\
\text { STEL }\end{array}$ \\
\hline ACGIH & & 10 \\
NIOSH & 5 & 10 \\
OSHA & 5 & 10 \\
\hline
\end{tabular}


Table 4. Potential routes of exposure to di-(2-ethylhexyl) phthalate (DEHP) during HEPA filter testing.

\begin{tabular}{||l|l|l||}
\hline Route & Activity or Work Practice & Exposure Potential \\
\hline Ingestion & $\begin{array}{l}\text { Cross-contamination of clothing or hands prior } \\
\text { to eating, drinking, smoking, etc. }\end{array}$ & $\begin{array}{l}\text { Minimal provided proper hygiene practices are } \\
\text { followed and personal protective equipment is worn } \\
\text { during activities with the potential for contact with } \\
\text { DEHP }\end{array}$ \\
\hline Dermal & Spills and splashes during generator filling & $\begin{array}{l}\text { Minimal if pouring is controlled and gloves and } \\
\text { eyewear are worn } \\
\text { Liquid residue on delivery system after use } \\
\text { Maintenance and repair work inside ductwork } \\
\text { use and gloves and eyewear are worn }\end{array}$ \\
\hline Inhalation & $\begin{array}{l}\text { Leakage in generator or delivery hose during after } \\
\text { aerosol release into ductwork } \\
\text { Premature aerosol generation or early removal } \\
\text { of delivery hose from ductwork } \\
\text { Poorly sealed ductwork }\end{array}$ & $\begin{array}{l}\text { potential source of contamination and eyewear and } \\
\text { gloves are worn }\end{array}$ \\
$\begin{array}{l}\text { Potential for short-term, high-concentration } \\
\text { exposure before condition is visually identified and } \\
\text { corrected } \\
\text { Potential for short-term, high-concentration } \\
\text { exposure before condition is visually identified and } \\
\text { corrected } \\
\text { Minimal unless ductwork and filter bank are located } \\
\text { on the positive pressure side of the fan (e.g., } \\
\text { downstream from the fan) }\end{array}$ \\
\hline
\end{tabular}


Table 5. Properties of several potential DEHP substitutes.

\begin{tabular}{|c|c|c|c|c|c|c|}
\hline & DEHP & $\begin{array}{l}\text { Di- } \\
\text { (Ethylhexyl) } \\
\text { Sebacate. }\end{array}$ & Corn Oil & $\begin{array}{l}\text { Mineral } \\
\text { Oil }\end{array}$ & $\begin{array}{l}\text { Polyethylene } \\
\text { Glycol (PEG } \\
\text { 400) }\end{array}$ & Emery 3004 \\
\hline Molecular weight & 390.5 & 426.8 & Varies & Varies & $380-420$ & Not available \\
\hline Density $(\mathrm{g} / \mathrm{mL}) @ 20^{\circ} \mathrm{C}$ & 0.986 & 0.913 & 0.92 & 0.82 & $\sim 1.1$ & 0.80 \\
\hline Form@20 $\mathrm{C}$ & Liquid & Liquid & Liquid & Liquid & Liquid & Liquid \\
\hline Stability & High & High & Moderate & High & High & High \\
\hline Boiling point, ${ }^{\circ} \mathrm{C}\left({ }^{\circ} \mathrm{F}\right)$ & $384(724)$ & $240(464)$ & Varies & $\begin{array}{l}260-330 \\
(500- \\
626) \\
\end{array}$ & $>200(>392)$ & $401(754)$ \\
\hline Flash point, ${ }^{\circ} \mathrm{C}\left({ }^{\circ} \mathrm{F}\right)$ & $215(420)$ & $210(410)$ & $254(490)$ & $\begin{array}{l}132-229 \\
(270- \\
444) \\
\end{array}$ & $196(385)$ & $222(432)$ \\
\hline Autoignition temp., ${ }^{\circ} \mathrm{C}\left({ }^{\circ} \mathrm{F}\right)$ & $390(735)$ & Not available & $393(740)$ & Varies & Varies & $343(650)$ \\
\hline Vapor pressure@20º, mm Hg & $<1$ & $<1$ & $<1$ & $\sim 1-2$ & $<1$ & $<1$ \\
\hline Viscosity@20 @ C, centipoises & 81.4 & 17.4 & Varies & 52.4 & 105 & Not available \\
\hline Count median diameter (um) & 0.25 & 0.22 & 0.25 & 0.27 & 0.3 & $0.20-0.30$ \\
\hline
\end{tabular}

